\title{
Foveal and parafoveal choroidal thickness pattern measuring by swept source optical coherence tomography
}

\author{
Pear Pongsachareonnont ${ }^{1,2}$ - Thanapong Somkijrungroj ${ }^{1,2}$ • Buravej Assavapongpaiboon ${ }^{1,2}$ • \\ Theerada Chitamara ${ }^{1,2} \cdot$ Maytavee Chuntarapas $^{1,2} \cdot$ Disorn Suwajanakorn $^{1,2}$
}

Received: 5 June 2018 / Revised: 3 February 2019 / Accepted: 24 February 2019 / Published online: 8 April 2019

(c) The Royal College of Ophthalmologists 2019

\begin{abstract}
Objective To evaluate the choroidal thickness (CT) in foveal and parafoveal regions in Thai adults using swept-source optical coherence tomography (SS-OCT).

Methods We enrolled healthy volunteers $\geq 18$ years of age from King Chulalongkorn Memorial Hospital, Thailand, during September 2015 to March 2016. Optical coherence tomography (OCT) of the macula was performed, and subfoveal CT was measured manually using a line scan. Average thicknesses of retinal and choroidal layers in regions of the Early Treatment Diabetic Retinopathy Study grid were measured automatically. A multivariate analysis was conducted to determine correlations between CTs in the foveal and parafoveal regions and retinal layers.

Results Altogether, 144 eyes from 144 subjects ( 29 men, 115 women; mean age 41 years) were studied. The mean foveal CT was $282.4 \pm 13.8 \mu \mathrm{m}$. It was thicker in the temporal fovea than in the nasal fovea $(p<0.001)$ and thicker in men than in women. Multivariate analysis showed that age and sex were significantly negatively correlated with the thickness of the retina, ganglion cell layer, outer retinal layer, and choroid but not of the nerve fiber layer. Regression analysis revealed that the CT decreased approximately $1.5 \mu \mathrm{m}$ per year.

Conclusions Age and sex significantly influence choroidal thickness. Macular CT in a healthy eye thins with age. CT decreases with age faster at distances away from the foveal center than at the center. Subfoveal CT was greater than the mean CT. Parafoveal CT should be evaluated to identify specific retinal-choroidal disease.
\end{abstract}

\section{Introduction}

Choroidal thickness (CT) plays an important role in the pathogeneses and predictions of pachychoroid entities, central serous chorioretinopathy [1,2], polypoidal choroidal vasculopathy [3], age-related macular degeneration (AMD) $[4,5]$, posterior uveitis [6], Vogt-Koyanagi-Harada

Supplementary information The online version of this article (https:// doi.org/10.1038/s41433-019-0404-4) contains supplementary material, which is available to authorized users.

$\checkmark$ Pear Pongsachareonnont

pear.p@chulahospital.org

1 Vitreoretinal Research Unit, Department of Ophthalmology, Faculty of Medicine, Chulalongkorn University, Bangkok, Thailand

2 King Chulalongkorn Memorial Hospital, Thai Red Cross Society, Bangkok, Thailand disease, multiple evanescent white dot syndrome, and multifocal choroiditis. CT is also associated with other pathological eye conditions, such as high myopia [7, 8] and glaucoma [9, 10]. In addition, physiological conditionsage [11, 12], sex [12], diurnal variation [13], choroidal blood flow [14], axial length [15], and myopia [16]—affect CT in normal populations. Assessment of CT provides diagnostic power for differentiating between healthy and pathological eyes, including neovascularized AMD, central serous chorioretinopathy, polypoidal choroidal vasculopathy [3], posterior uveitis [6], and high myopia. Some systemic disorders have also been shown to be related to choroidal changes, including diabetes, hypertension, hyperlipidemia, ankylosing spondylitis, Behçet's disease, sarcoidosis, Sturge-Weber syndrome, and Alzheimer's disease [17]. Many physiological conditions, including diurnal variation [13], age, and sex, also affect CT [18].

The development of indocyanine green angiography and ultrasonography allowed the first visualization of choroidal structures. This traditional imaging of the choroid, however, 
was insufficient for quantitative assessments because of its limited resolution. With the development of optical coherence tomography (OCT), the retinal layers were more clearly demonstrated with nearly histology-level details. Currently, spectral domain (SD) imaging is widely used and offers significant advantages over the earlier time-domain imaging [19]. Imaging of the deeper layer (i.e., choroid), however, was still poorly detailed by SD-OCT. Enhanced depth imaging (EDI) was developed to focus more on the choroidal layer by reducing scattering effects and depthdependent reduction in sensitivity [20]. With EDI OCT, however, the image quality of the retinal layers was traded off to obtain details of the choroid.

Swept-source (SS) OCT has now been developed, with a tunable laser operating using a longer-wavelength light source $(\sim 1050 \mathrm{~nm})$ and a high-speed photodetector instead of a spectrometer. SS-OCT provides better scan speed and deeper images than SD-OCT [21]. With an operating wavelength of $1 \mu \mathrm{m}$ and less variable sensitivity with increasing depth (sensitivity roll-off), SS-OCT provides less susceptibility to scattering in cataract cases and better penetration through retinal pigmented epithelium to visualize deeper layers, such as those of the choroid [22]. This ability enables SS-OCT to penetrate deep tissues and provide a picture of both the retina and choroid simultaneously. Hence, SS-OCT is considered the instrument of choice for studying the choroidal layer.

CT varies among ethnic groups [11, 12, 23-25] which results in different reference values for normal eyes among populations. Moreover, a previous study showed poor agreement about retinal thickness (RT) measurements by different OCT machines in healthy eyes [26]. Despite the good correlation, RTs measured by various devices showed significant differences [27]. The aims of the current study were to measure the $\mathrm{CT}$ of normal eyes as a reference for an adult Thai population using SS-OCT and to evaluate the association of foveal and parafoveal anatomy and that of the choroid.

\section{Materials and methods}

This cross-sectional study was conducted at King Chulalongkorn Memorial Hospital, Bangkok, Thailand. The Faculty of Medicine, Chulalongkorn University institutional review board approved the study (IRB No. 260/58). Healthy volunteers were prospectively recruited in the hospital from September 2015 to March 2016. The inclusion criteria were: (1) healthy subjects aged $\geq 18$ years; (2) best corrected visual acuity in the study eye $>20 / 30$ Snellen; and (3) spherical equivalent measured by autorefraction less than \pm 3 diopters. The exclusion criteria were: (1) inability to undergo scanning by the instrument; (2) a past medical history of diabetes, hypertension, cancer, and/or endocrine disease by chart record and patient history; (3) myopia or hyperopia with a spherical equivalent of $>3$ diopters; (4) intraocular pressure $>21 \mathrm{~mm} \mathrm{Hg}$; (5) presence of ocular disease including retinal disease, choroidal disease, glaucoma, and uveitis; and (6) previous ocular surgery of the eye. We considered an eye as a single study unit and only the left eyes were included in the analysis.

Informed consent was obtained from all subjects prior to enrollment in the study. The study was registered with the Thai Clinical Trial Registration before the study [TCTR20150526001].

We recorded the patients' demographic data including age and sex, best corrected visual acuity (BCVA), and the results of autorefraction measurements and air-puff tonometry. As is known from previous publications, age influences CT. Hence, the study group was divided into five subgroups according to their age: $18-30,31-40,41-50,51-$ 60 , and $>61$ years.

Visual acuity was measure using a modified numerical Early Treatment Diabetic Retinopathy Study (ETDRS) chart $4 \mathrm{~m}$ distant from the patient. SS-OCT imaging was performed using the DRI OCT Triton ${ }^{\mathrm{TM}}$ apparatus (software version 1.21; Topcon Medical Systems, Tokyo, Japan). This instrument had a center wavelength of $1050 \mathrm{~nm}$ with a scanning rate of 100,000 A-scans/s, yielding resolutions of $8 \mu \mathrm{m}$ (axial) and $20 \mu \mathrm{m}$ (transverse) in tissue [28].

\section{Imaging protocol}

OCT images of two scan types, horizontal line and threedimensional volumetric scans, were obtained by a trained single operator. One image from each scan type was taken from each patient. Any image with poor quality was rejected and another image was retaken until a good quality one is achieved. Only good-quality images were included for analysis.

- A horizontal, high-definition, 12-mm line scan was obtained that included the fovea and optic nerve head area for visualizing the choroid-sclera interface and analyzing CT measurements.

- A three-dimensional, wide, macular volumetric scan $(9 \times 12 \mathrm{~mm})$ for the average CT of each segment according to the ETDRS grid and automatically calculated by the OCT software. The ETDRS grid was composed of three circles with diameters of 1,3 , and 6 $\mathrm{mm}$, respectively, all with the same center, as shown in Fig. 1. The foveal area was taken to be that area surrounded by the innermost circle $\left(0.79 \mathrm{~mm}^{2}\right)$, and its average thickness was calculated. The two outer circles were divided into four quadrants-superior, temporal, inferior, nasal—which then were divided into an inner 
region $\left(1.57 \mathrm{~mm}^{2}\right)$ and outer region $\left(5.30 \mathrm{~mm}^{2}\right)$. The average full RTs and the CTs for each region were automatically measured: nerve fiber layer (NFL), ganglion cell complex (GCC) (which included the NFL and ganglion cells), and inner plexiform layer.

\section{Parameter measurements}

Each parameter was evaluated according to its location on the ETDRS grid extracted from OCT machine (Fig. 1). The subfoveal choroidal thickness (SFCT) was manually measured according to a vertical line perpendicular to the outer border of the hyperreflective retinal pigmented epithelium to the inner border of the choroid-sclera interface, defined as the inner hyperreflective band of sclera underneath the fovea. To determine the parafoveal choroidal thickness, three further measurements were performed every $1000 \mu \mathrm{m}$ temporally from the center of the fovea (T1, T2, T3) and three more nasal measurements (N1, N2, N3). All the measurement was performed by two well-trained physicians (BA and DS) who were masked. The outer retinal layer (ORL) was measured from the inner nuclear layer to the inner border of the retinal epithelium.

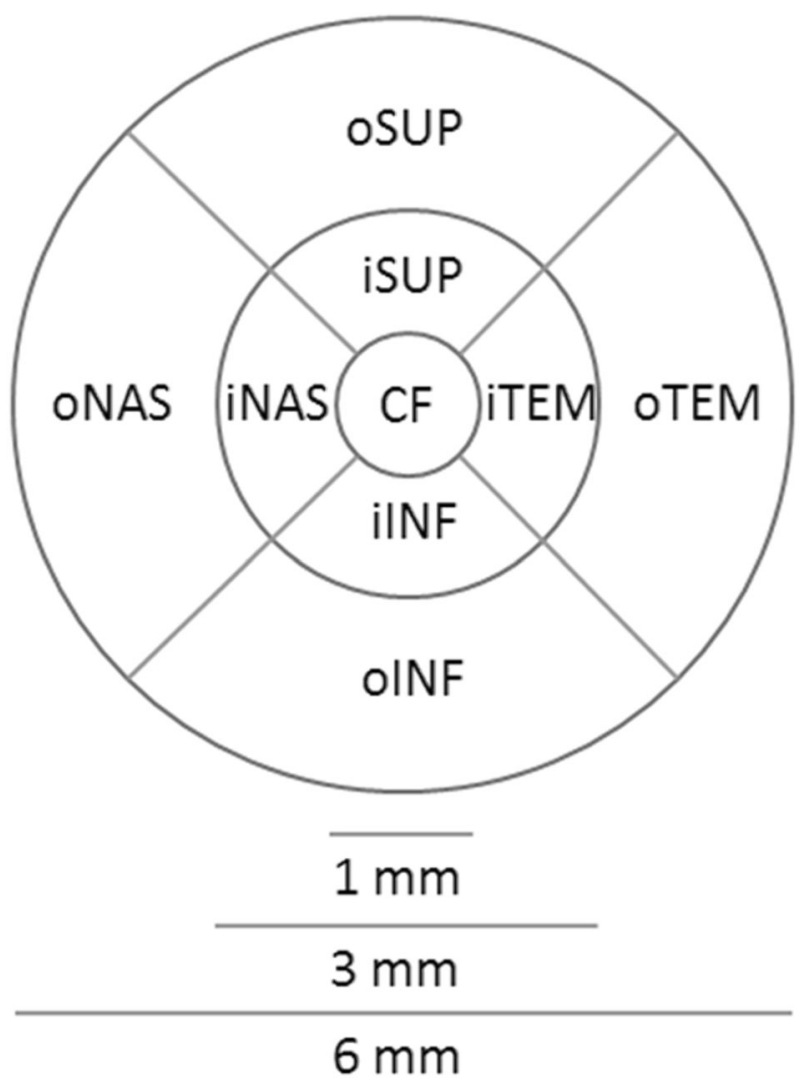

Fig. 1 Nine areas on the ETDRS grid of the left eye

\section{Data analysis and statistics}

Sample size estimation was calculated from the mean of choroidal thickness using the formula of $n=Z_{1-\alpha / 2}^{2} \sigma^{2} / d^{2}$ with $\alpha=0.05, \sigma=84$ microns and $d=2$. The estimate sample size was 81 eyes. Baseline characteristics of subjects were analyzed using descriptive statistics. The categorical data are shown in percent, whereas continuous data are presented as means \pm standard deviation (SD). The means of each retinal and choroidal layer were calculated for all nine regions of the ETDRS grid. The difference between the mean CTs in two subgroups was analyzed using an independent $t$-test. Analysis of variance was used to compare more than two subgroups. Analysis of covariance was applied to compare differences in RTs and CTs between the two sexes, with age as the covariate. Pearson's correlation coefficients were used to evaluate bivariate correlations. The relations between macular RT and CT and sex, age, and spherical equivalence were investigated by linear and stepwise multiple regression analyses. Inter-observer reproducibility was evaluated between the two evaluators using the intraclass correlation coefficient for each variable measured. All statistical analyses were evaluated at a significance level of 0.05 and a $95 \%$ confidence interval. Statistical analysis was performed with SPSS version 22.0 (IBM, Armonk, NY, USA).

\section{Results}

Altogether, 144 eyes from 144 healthy subjects were included in the study. The demographic data of all subjects are shown in Table 1.

Table 1 Baseline demographic data for the 144 subjects in this study

\begin{tabular}{ll}
\hline Characteristic & Value \\
\hline Female sex & $115(80 \%)$ \\
Age (years) & $41 \pm 13$ years $(18-85$ years) \\
Age group (years) & $36(25 \%) ; 63.9 \%$ female \\
$18-30$ & $31(21.4 \%) ; 77.4 \%$ female \\
$31-40$ & $38(26.4 \%) ; 86.8 \%$ female \\
$41-50$ & $31(21.5 \%) ; 86.5 \%$ female \\
$51-60$ & $8(5.6 \%) ; 100 \%$ female \\
$\geq 61$ & $84.2 \pm 6.4(61-99)$ \\
BCVA score & $-0.2 \pm 1.2 \mathrm{D}$ \\
SE &
\end{tabular}

Data are given as the number (\%), mean $\pm \mathrm{SD}$, and/or the range $B C V A$ best corrected visual acuity, $S E$ spherical equivalent 


\section{Retinal, NFL, GCC, and choroidal thickness in healthy subjects}

The mean RT for all 144 eyes was $282.4 \pm 13.8 \mu \mathrm{m}$ (range 241.1-321.2 $\mu \mathrm{m}$ ). The mean RT for each layer and the CTs are shown in Table 2. The distinct topographical variation of the retina in different regions and thickness patterns (Appendix) shows that RT increased in the following order: central foveal, outer nasal, outer inferior, outer superior, outer temporal, inner nasal, inner inferior, inner superior, and inner temporal regions. Among the nine independent regions, the central foveal region had the thinnest layer. The inner region had a thicker layer than the outer region of the retinal layer, the GCC, and the choroidal layer. The thickness of the NFL, however, shows an inverse pattern, so the outer region was thicker than the inner region. The temporal area had a thicker NFL than the nasal region (mean differences of $26.1 \mu \mathrm{m}$ and $3.0 \mu \mathrm{m}$ for the outer and inner regions, respectively: $p<0.001$ and $p<0.001$, paired $t$-test).

The overall mean macular NFL and GCC thicknesses were $29.7 \pm 2.9 \mu \mathrm{m}$ and $74.8 \pm 6.2 \mu \mathrm{m}$, respectively, and correlations with the total RT were $0.489(p<0.001)$ and $0.836(p<0.001)$, respectively. The correlation between the NFL and GCC thicknesses was $0.582(p<0.001)$. The temporal area had thicker NFL than the nasal area, with a mean difference of $23.7 \mu \mathrm{m}(p<0.001)$. The average ORL thickness was $178 \pm 8.7 \mu \mathrm{m}$, the correlation of which with the total retinal layer was $0.818(p<0.001)$.

The mean total CT from all areas of the ETDRS grid was $257.0 \pm 64.3 \mu \mathrm{m}$ (range $86.9-427.0 \mu \mathrm{m}$ ). The correlation between the CT and RT was $0.135(p=0.108)$. There was no correlation between the CT and the NFL or GCC ( $p=0.797$ and $p=0.727$, respectively). The choroid exhibited a distribution pattern different from that of the retinal layers, with the central foveal segment of the choroid not the thinnest sector. The mean foveal CT was $265.5 \pm$ $74.2 \mu \mathrm{m}$. The mean thickness of the CT in the macular region varied from thinner to thicker as follows: outer temporal, outer nasal, outer inferior, inner temporal, inner nasal, central fovea, inner inferior, outer superior, and inner superior region. The choroidal layer was thickest in the superior subfield, followed by that in the inferior, nasal, and temporal subfields. Compared with the nasal area, the foveal temporal area was thicker, with mean differences of $23.7 \mu \mathrm{m}$ and $1.1 \mu \mathrm{m}$ for the outer and inner regions, respectively ( $p<0.001$ and $p=0.747$, respectively; paired $t$-test).

\section{Effects of sex, age, and spherical equivalence on normal retina, NFL, GCC, and choroidal thickness}

In the subgroup analysis, the mean RT and the thickness of the NFL, GGC, ORL, and choroid in the men were $289.6 \pm 13.4,29.9 \pm 1.6,77.9 \pm 5.5,182.3 \pm 9.3$, and 280.1 $\pm 61.9 \mu \mathrm{m}$, respectively. In the women, the corresponding measurements were $280.5 \pm 13.3,29.7 \pm 2.7,74.1 \pm 6.1$, $177.1 \pm 8.3$, and $251.1 \pm 60.8 \mu \mathrm{m}$, respectively. The total retina, GCC, and ORL were slightly thicker in the men than in the women. Similarly, the choroid was significantly thicker in the men than in the women $(p=0.027)$, although there was no statistically significant difference in the thickness of the NFL in the men and women $(p=0.770)$. Comparisons of the thickness of the retina, NFL, GCC, and choroid across the various age groups are shown in Table 3. Although there was prominent age-related reduction in choroid thickness, it seems that NFL thickness does not significantly decrease with age.

The linear regression analysis showed that age and female sex were significantly negatively correlated with the
Table 2 Thicknesses of the layers of each region of the ETDRS grid $(n=144)$

\begin{tabular}{llllll}
\hline Region & Retina & Nerve fiber & Ganglion cell complex & Outer retina & Choroid \\
\hline Total & $282.4 \pm 13.8$ & $29.7 \pm 2.9$ & $74.8 \pm 6.2$ & $178.1 \pm 8.7$ & $257.0 \pm 64.3$ \\
oSUP & $276.2 \pm 14.4$ & $40.2 \pm 4.4$ & $67.3 \pm 6.1$ & $168.7 \pm 8.3$ & $266.5 \pm 68.2$ \\
iSUP & $309.5 \pm 16.5$ & $27.2 \pm 2.4$ & $90.9 \pm 8.6$ & $191.4 \pm 10.1$ & $269.6 \pm 66.9$ \\
oTEM & $291.7 \pm 15.5$ & $50.1 \pm 6.2$ & $73.5 \pm 6.2$ & $168.8 \pm 12.6$ & $221.8 \pm 68.4$ \\
iTEM & $309.9 \pm 16.9$ & $25.2 \pm 2.2$ & $90.2 \pm 8.9$ & $194.4 \pm 10.3$ & $262.5 \pm 74.5$ \\
oINF & $263.6 \pm 13.5$ & $42.7 \pm 5.4$ & $63.3 \pm 5.2$ & $158.2 \pm 11.4$ & $251.8 \pm 70.2$ \\
iINF & $307.3 \pm 15.6$ & $29.0 \pm 2.5$ & $90.9 \pm 8.2$ & $187.4 \pm 9.4$ & $265.8 \pm 78.5$ \\
oNAS & $258.0 \pm 13.0$ & $24.0 \pm 1.2$ & $69.0 \pm 5.9$ & $165.3 \pm 10.4$ & $245.5 \pm 64.8$ \\
iNAS & $297.2 \pm 15.6$ & $22.3 \pm 1.3$ & $85.8 \pm 8.0$ & $188.3 \pm 12.4$ & $263.6 \pm 70.4$ \\
Subfoveal CT & $227.9 \pm 20.7$ & $5.4 \pm 2.7$ & $42.4 \pm 8.5$ & $180.6 \pm 15.6$ & $265.5 \pm 74.2$ \\
\hline Values & &
\end{tabular}

Values are the mean \pm SD in micrometers $(\mu \mathrm{m})$

ETDRS Early Treatment Diabetic Retinopathy Study, CF central fovea, oSUP outer superior region, iSUP inner superior region, $O T E M$ outer temporal region, $i T E M$ inner temporal region, $o I N F$ outer inferior region, $i I N F$ inner inferior region, $o N A S$ outer nasal region, $i N A S$ inner nasal region, $C T$ choroidal thickness 
Table 3 Thickness of the layers of the components of the eye, by age group

\begin{tabular}{lcccccr}
\hline Layer & $\begin{array}{l}18-30 \text { Years } \\
(n=36)\end{array}$ & $\begin{array}{l}31-40 \text { Years } \\
(n=31)\end{array}$ & $\begin{array}{l}41-50 \text { Years } \\
(n=38)\end{array}$ & $\begin{array}{l}51-60 \text { Years } \\
(n=31)\end{array}$ & $\begin{array}{l}>60 \text { Years } \\
(n=8)\end{array}$ & $p^{\mathrm{a}}$ \\
\hline RT & $289.5 \pm 10.5$ & $281.6 \pm 14.0$ & $279.4 \pm 14.7$ & $282.0 \pm 12.4$ & $282.4 \pm 13.8$ & $<0.001$ \\
NFL & $30.4 \pm 1.7$ & $29.3 \pm 2.4$ & $29.9 \pm 3.9$ & $29.6 \pm 3.0$ & $29.7 \pm 2.9$ & 0.300 \\
GCC & $77.4 \pm 3.9$ & $73.5 \pm 6.3$ & $74.6 \pm 6.2$ & $74.5 \pm 6.8$ & $74.8 \pm 6.2$ & 0.020 \\
ORL & $182.3 \pm 8.1$ & $178.8 \pm 9.3$ & $175.6 \pm 8.5$ & $177.9 \pm 7.2$ & $169.6 \pm 6.2$ & $<0.001$ \\
CT & $284.2 \pm 73.0$ & $254.3 \pm 56.8$ & $264.7 \pm 45.3$ & $233.4 \pm 61.8$ & $199.5 \pm 79.5$ & 0.001 \\
\hline
\end{tabular}

Values are the mean \pm SD in micrometers $(\mu \mathrm{m})$

$R T$ retina, $N F L$ nerve fiber layer, $G C C$ ganglion cell complex, $O R L$ outer retinal layer, $C T$ subfoveal choroidal thickness

${ }^{a}$ Analysis of variance thickness of the retina, GCC, ORL, and choroid but not the NFL (Appendix). The spherical equivalent was significantly negatively correlated with the thickness of the retina, NFL, GCC, but not the choroid and ORL. After adjusting for every factor with the stepwise multiple regression analysis, age and sex still showed significant correlations with the retina, ORL, and choroid but not the NFL. Only sex, not age, showed the significant correlation with the GCC. The spherical equivalent, however, shows a significant correlation only for the GCC. The mean CT showed a negative correlation with age $(p<0.001)$, with a regression coefficient of $r^{2}=0.097$. With the regression formula, the mean CT decreased approximately $1.5 \mu \mathrm{m}$ for each year's increase in age.

\section{CT by manual measurement}

The intraclass correlation coefficient between 2 observers for SFCT and parafoveal choroidal thickness was 0.925 (95\% confidence interval 0.919-0.931). The mean SFCT determined by manual line measurement was $326.0 \pm 86.2 \mu \mathrm{m}$. There was a good correlation between the CT and SFCT thickness $(r=0.736, p<0.001)$. An obvious age-related reduction was shown in the CT (Table 3). The mean CT determined by manual evaluation at $\mathrm{N} 3(3000 \mu \mathrm{m}$ nasally from the foveal center) was $199.3 \mu \mathrm{m}, \mathrm{N} 2(2000 \mu \mathrm{m}$ nasally from the foveal center) $262.6 \mu \mathrm{m}, \mathrm{N} 1$ (1000 $\mu \mathrm{m}$ nasally from the foveal center) $305.4 \mu \mathrm{m}, \mathrm{T} 1(1000 \mu \mathrm{m}$ temporally from the foveal center) $318.7 \mu \mathrm{m}, \mathrm{T} 2(2000 \mu \mathrm{m}$ temporally from the foveal center) $326.0 \mu \mathrm{m}$, and T3 (3000 $\mu \mathrm{m}$ temporally from the foveal center) $301.7 \mu \mathrm{m}$. The regression analysis found that the CT decreased significantly with age at peripheral measuring points $(>1000 \mu \mathrm{m}$ from the subfoveal point), whereas the decrement was minimal (without statistical significance) within the central $1000 \mu \mathrm{m}$ area. The correlation of age and CT at locations N3, N2, N1, SFCT, T1, $\mathrm{T} 2$, and T3 were $-0.224(p<0.001),-0.140(p=0.018)$, $-0.098(p=0.095),-0.064(p=0.278),-0.076(p=0.20)$, $-0.159(p=0.007)$, and $-0.198(p=0.001)$, respectively.

\section{Discussion}

The present study provided a normal reference value for CT measured by the SS-OCT in an adult Thai population. To our knowledge, it is the first study to determine the baseline thickness of the choroid of healthy Thai volunteers using SS-OCT with the ETDRS grid and to assess the relations among clinical variables including sex, age, spherical equivalence, and thickness of the retina, NFL, and GCC. SS-OCT, which projects longer wavelengths (allowing better penetration through pigmented tissues), more clearly shows the choroidal layer [29]. The choroid-sclera interface can be clearly demonstrated in $100 \%$ of eyes using SS-OCT compared with $73.6 \%$ in the SD-OCT with EDI [30]. Measurement of the retina, ganglion cell-related layers (GCC), and choroid were automatically provided by SSOCT with confirmed reliability of measurement, especially for the choroid [31, 32].

Many studies have reported measuring the CT of healthy adult subjects using SS-OCT (Table 4). Although there were no statistically significant differences or correlations of the $\mathrm{CT}$ among ethnic groups reported in the previous studies $[12,33]$, in addition, Asians tended to have thinner CT than Caucasians. In addition to ethnicity, the factors that affect CT are age, sex, and the set point for measuring the outer border of the choroidal layer.

In this study, the mean SFCT was approximately 326 $\mu \mathrm{m}$ by SS-OCT, whereas the mean SFCT was $294 \mu \mathrm{m}$ and $279 \mu \mathrm{m}$ by SD-OCT EDI, as reported by Phasukkijwatana et al. [34] and Jirarattanasopa et al. [35], respectively. The loss of SFCT predicted by our study was $0.85 \mu \mathrm{m}$ per year, whereas it was $1.22 \mu \mathrm{m}$ and $2.67 \mu \mathrm{m}$ per year, respectively. Those two studies used the same ethnic population but with different OCT modalities and did not control the refractive error, which allows bias in the mean SFCT. Zafar et al. [36]. and Copete et al. [37], however, reported no significant differences in the $\mathrm{CT}$ measured with SS-OCT and SD-OCT [36, 37]. In contrast, Matsuo et al. [38] showed that CT measurements using 


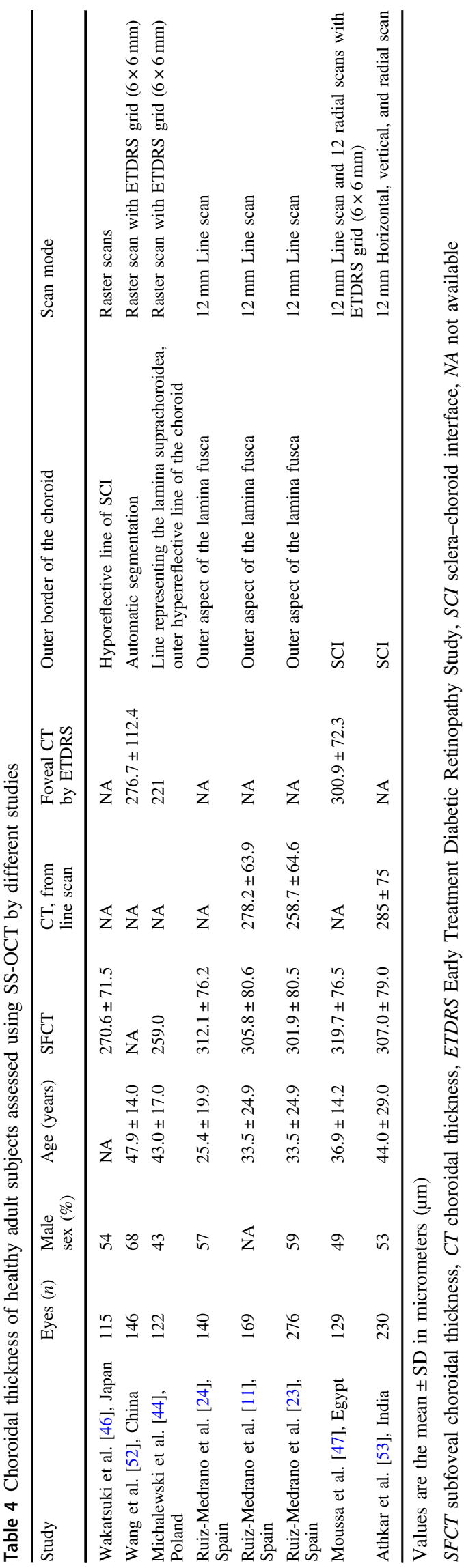

SS-OCT were slightly greater than those obtained using SD-OCT. This is possible because SS-OCT gives higherquality images on which the outer choroidal border could be identified at the outer aspect of the choroid-sclera interface, rather than the outer limit of the choroidal vessels.

In the current study, the patient's sex was associated with $\mathrm{CT}$, and the mean $\mathrm{CT}$ was thicker in men than in women, with statistical significance (280.1 vs. $251.1 \mu \mathrm{m})$. Population-based studies have also shown that men have thicker CT than women [18, 37-41]. This difference may be explained by the higher basal sympathetic tone in women, which might cause vasoconstriction due to activation of sympathetic $\alpha$-adrenoceptors [42, 43]. The relation between patient's sex and CT is still controversial. Previous publications demonstrated an independent association between age, sex, axial length, myopic refractive error, and the $\mathrm{CT}[18,40,44]$. It has also been reported, however, that older age, female sex, greater axial length, and high myopic refractive error are associated with thinner CT.

In the present study, a linear regression analysis showed a distinct age-related reduction in the mean CT, with a significant negative correlation between the two. Age was significantly correlated with the thickness of the choroid after adjusting for sex and spherical equivalence. The decrease in CT is correlated with a histopathologically proved decrease in vascular density and decreased choriocapillaris diameter [45]. This finding was consistent with those in other studies [18, 40, 41]. As a result, in elderly individuals, retinal pigment epithelium and the outer retina including photoreceptors may receive less oxygen and other metabolites, which could lead to various age-related retinal diseases. The degenerative changes might preserve the subfoveal region as it is an important area for vision. Ramrattan et al. [45] also reported histological decreases in the choriocapillaris and choroidal capillary lumen in normal human macula with AMD. Interestingly, CT is significantly negatively correlated with age, while SFCT is not. It is notable, however, the single-point choroidal measurements may provide misleading indications of choroidal changes. Thus, a mean CT or multipoint evaluation of the choroid is suggested when evaluating foveal CT.

The choroid was thickest at the foveal center and then decreased as measurements moved away $(>1000 \mu \mathrm{m})$ from the center, occurring more prominently on the nasal side than on the temporal side. A similar profile pattern was described in previous studies [23, 37]. Hence, the SFCT tended to be thicker than the mean CT [46-48]. One should be aware of whether the mean CT or the SFCT is being reported when comparing 
CTs among studies. The mean CT and SFCT have a tendency to become thinner with increasing age, although without statistical significance. However, the stronger correlation was better observed at the point measured closer to the fovea on both the temporal and nasal sides. Ruiz-Medrano et al. [23] reported a high correlation between age and CT measured $1000 \mu \mathrm{m}$ distance from the foveal center. This correlation, however, was found to be stronger the farther away the CT measurements were temporally from the foveal center.

We believe that this is the first study in an Asian population using SS-OCT to evaluate CT in the macular region. $\mathrm{CT}$ in the parafoveal region is important to determine the pachychoroid disease spectrum that was reported by Gallego-Pinazo et al. [49]. The non-subfoveal choroidal thickness might be important in the pachychoroid syndrome reported by Phasukkijwatana et al. [50], who showed that nasal choroid is thicker than temporal choroid.

The main strength of the present study is the measurement of CT shown by both automated segmentation and manual measurement. Furthermore, there were negative correlation of subfoveal CT and parafoveal CT with age. This study gave provided the results of OCT measurement thickness of whole retina layer, NFL and GCL; which can use as normal references number of retina layer thickness, foveal, and parafoveal regions measuring by SS-OCT in adult Asian population.

There were, however, some limitations of this study. First, the proportion of men and women was not equivalent, with approximately $80 \%$ of the subjects being women. As previous population-based studies have also shown that men have thicker CT than women, the value of mean CT from the current study may underestimate the real mean CT thickness. Second, this study primarily focused on an adult population, and hence the normal reference for CT in a pediatric Thai population is still unknown. Third, choroidal thickness value can be varied because of manual measurement by different persons. However, the intraclass correlation showed excellent reliability [51]. Fourth, other factors which might be correlated to CT were not included in our study, such as diurnal variation and body mass index. Furthermore, undiagnosed diabetic patients can unintentionally be included in the current study as the recruitment process was done by chart review, not including blood sugar test.

In conclusion, age and sex significantly influence CT. The macular CT in a healthy eye diminishes with age which there were higher negative correlation for the CT with the distant form foveal center. Men are prone to have a thicker CT than women. In addition, the SFCT was thicker than the mean CT. Parafoveal CT should be evaluated to identify specific retinal-choroidal diseases.

\section{Summary}

\section{What was known before}

- Choroidal thickness in Asians tended to be thinner compared to Caucasians.

- Choroidal thickness decreases with age.

\section{What this study adds}

- Foveal and parafoveal structure of choroid in the Thai population.

- The thinning of choroidal associated with aging started from parafoveal area and affected mean choroidal thickness, while subfoveal choroidal thickness has less effect.

Acknowledgements We thank Nancy Schatkenfrom Edanz Group (www.edanzediting.com/ac) for editing a draft of this manuscript.

Funding This study was funded by Topcon Instrument, Thailand. Ltd. The company had no part in setting up the study design analysis or in overseeing the results in the manuscript.

\section{Compliance with ethical standards}

Conflict of interest The authors declare that they have no conflict of interest.

Publisher's note: Springer Nature remains neutral with regard to jurisdictional claims in published maps and institutional affiliations.

\section{References}

1. Imamura Y, Fujiwara T, Margolis R, Spaide RF. Enhanced depth imaging optical coherence tomography of the choroid in central serous chorioretinopathy. Retina. 2009;29:1469-73. https://doi. org/10.1097/IAE.0b013e3181be0a83

2. Maruko I, Iida T, Sugano Y, Ojima A, Sekiryu T. Subfoveal choroidal thickness in fellow eyes of patients with central serous chorioretinopathy. Retina. 2011;31:1603-8. https://doi.org/10. 1097/IAE.0b013e31820f4b39

3. Ma, L, Tang SM, Rong SS, Chen H, Young AL, Kumaramanickavel G, et al. Association of PEDF polymorphisms with age-related macular degeneration and polypoidal choroidal vasculopathy: a systematic review and meta-analysis. Sci Rep. 2015;5:9497. https://doi.org/10.1038/srep09497

4. Wood A, Binns A, Margrain T, Drexler W, Povazay B, Esmaeelpour $\mathrm{M}$, et al. Retinal and choroidal thickness in early age-related macular degeneration. Am J Ophthalmol. 2011;152:1030-8.e2. https://doi.org/10.1016/j.ajo.2011.05.021

5. Koizumi H, Yamagishi T, Yamazaki T, Kawasaki R, Kinoshita S. Subfoveal choroidal thickness in typical age-related macular degeneration and polypoidal choroidal vasculopathy. Graefe's Arch Clin Exp Ophthalmol. 2011;249:1123-8. https://doi.org/10. 1007/s00417-011-1620-1

6. Bittencourt MG, Kherani S, Ferraz DA, Ansari M, Nasir H, Sepah YJ, et al. Variation of choroidal thickness and vessel diameter in 
patients with posterior non-infectious uveitis. J Ophthalmic Inflamm Infect. 2014;4:14. https://doi.org/10.1186/s12348-0140014-z

7. Fujiwara T, Imamura Y, Margolis R, Slakter JS, Spaide RF. Enhanced depth imaging optical coherence tomography of the choroid in highly myopic eyes. Am J Ophthalmol. 2009;148:44550. https://doi.org/10.1016/j.ajo.2009.04.029

8. Chen W, Wang Z, Zhou X, Li B, Zhang H. Choroidal and photoreceptor layer thickness in myopic population. Eur J Ophthalmol. 2012;22:590-7. https://doi.org/10.5301/ejo.5000092

9. Cennamo G, Finelli M, Iaccarino G, de Crecchio G, Cennamo G. Choroidal thickness in open-angle glaucoma measured by spectral-domain scanning laser ophthalmoscopy/optical coherence tomography. Ophthalmologica. 2012;228:47-52. https://doi.org/ 10.1159/000336903

10. Maul EA, Friedman DS, Chang DS, Boland MV, Ramulu PY, Jampel HD, et al. Choroidal thickness measured by spectral domain optical coherence tomography: factors affecting thickness in glaucoma patients. Ophthalmology. 2011;118:1571-9. https:// doi.org/10.1016/j.ophtha.2011.01.016

11. Ruiz-Medrano J, Flores-Moreno I, Pena-Garcia P, Montero JA, Garcia-Feijoo J, Duker JS, et al. Analysis of age-related choroidal layers thinning in healthy eyes using swept-source optical coherence tomography. Retina. 2017;37:1305-13. https://doi.org/ 10.1097/iae.0000000000001347

12. Bafiq R, Mathew R, Pearce E, Abdel-Hey A, Richardson M, Bailey $\mathrm{T}$, et al. Age, sex, and ethnic variations in inner and outer retinal and choroidal thickness on spectral-domain optical coherence tomography. Am J Ophthalmol. 2015;160:1034-43.e1. https://doi.org/10.1016/j.ajo.2015.07.027

13. Han YS, Lim HB, Lee SH, Kim JY. Diurnal variation in choroidal and retinal thickness of the early treatment of diabetic retinopathy study macular subfields determined using swept-source optical coherence tomography. Ophthalmologica. 2015;233:192-7. https://doi.org/10.1159/000375538

14. Novais EA, Badaro E, Allemann N, Morales MS, Rodrigues EB, de Souza Lima R, et al. Correlation between choroidal thickness and ciliary artery blood flow velocity in normal subjects. Ophthalmic Surg Lasers Imaging Retin. 2015;46:920-4. https://doi. org/10.3928/23258160-20151008-04

15. Abbey AM, Kuriyan AE, Modi YS, Thorell MR, Nunes RP, Goldhardt R, et al. Optical coherence tomography measurements of choroidal thickness in healthy eyes: correlation with age and axial length. Ophthalmic Surg Lasers Imaging Retin. 2015;46:1824. https://doi.org/10.3928/23258160-20150101-03

16. El-Shazly AA, Farweez YA, ElSebaay ME, El-Zawahry WMA. Correlation between choroidal thickness and degree of myopia assessed with enhanced depth imaging optical coherence tomography. Eur J Ophthalmol. 2017;27:577-84. https://doi.org/10. 5301/ejo.5000936

17. Tan KA, Gupta P, Agarwal A, Chhablani J, Cheng CY, Keane PA, et al. State of science: choroidal thickness and systemic health. Surv Ophthalmol. 2016;61:566-81. https://doi.org/10. 1016/j.survophthal.2016.02.007

18. Wei WB, Xu L, Jonas JB, Shao L, Du KF, Wang S, et al. Subfoveal choroidal thickness: the Beijing Eye Study. Ophthalmology. 2013;120:175-80. https://doi.org/10.1016/j.ophtha.2012.07.048

19. Leitgeb R, Hitzenberger CK, Fercher AF. Performance of fourier domain vs. time domain optical coherence tomography. Opt Express. 2003;11:889-94. https://doi.org/10.1364/OE.11.000889

20. Spaide RF, Koizumi H, Pozonni MC. Enhanced depth imaging spectral-domain optical coherence tomography. Am J Ophthalmol. 2008; 146:496-500.

21. Wang Z, Reisman C, Liu J, Chan K. Introduction to swept source OCT. In: Michalewska Z, Nawrocki J, editors. Atlas of swept source optical coherence tomography. Cham: Springer; 2017. p.1-8
22. Unterhuber A, Povazay B, Hermann B, Sattmann H, ChavezPirson A \& Drexler W. In vivo retinal optical coherence tomography at $1040 \mathrm{~nm}$ - enhanced penetration into the choroid. Opt Express. 2005;13:3252-8.

23. Ruiz-Medrano J, Flores-Moreno I, Pena-Garcia P, Montero JA, Duker JS \& Ruiz-Moreno JM. Macular choroidal thickness profile in a healthy population measured by swept-source optical coherence tomography. Invest Ophthalmol Vis Sci. 2014;55:3532-42. https://doi.org/10.1167/iovs.14-13868

24. Ruiz-Medrano, J, Flores-Moreno I, Pena-Garcia P, Montero JA, Duker JS \& Ruiz-Moreno JM. Asymmetry in macular choroidal thickness profile between both eyes in a healthy population measured by swept-source optical coherence tomography. Retina. 2015;35:2067-73. https://doi.org/10.1097/iae.0000000000000590

25. Rhodes LA, Huisingh C, Johnstone J, Fazio MA, Smith B, Wang $\mathrm{L}$, et al. Peripapillary choroidal thickness variation with age and race in normal eyes. Invest Ophthalmol Vis Sci. 2015;56:1872-9. https://doi.org/10.1167/iovs.14-16179

26. Bahrami B, Ewe SYP, Hong T, Zhu M, Ong G, Luo K, et al. Influence of retinal pathology on the reliability of macular thickness measurement: a comparison between optical coherence tomography devices. Ophthalmic Surg Lasers Imaging Retin. 2017;48:319-25. https://doi.org/10.3928/23258160-20170329-06

27. Modjtahedi S, Chiou C, Modjtahedi B, Telander DG, Morse LS \& Park SS. Comparison of macular thickness measurement and segmentation error rate between stratus and fourier-domain optical coherence tomography. Ophthalmic Surg Lasers Imaging. 2010;41:301-10. https://doi.org/10.3928/15428877-20100430-02

28. Stanga PE, Tsamis E, Papayannis A, Stringa F, Cole, T \& Jalil A. Swept-source optical coherence tomography Angio (Topcon Corp, Japan): technology review. Dev Ophthalmol. 2016;56:1317. https://doi.org/10.1159/000442771

29. Ruiz-Moreno JM, Flores-Moreno I, Lugo F, Ruiz-Medrano J, Montero JA \& Akiba M. Macular choroidal thickness in normal pediatric population measured by swept-source optical coherence tomography. Invest Ophthalmol Vis Sci. 2013;54:353-9. https:// doi.org/10.1167/iovs.12-10863

30. Adhi M, Liu JJ, Qavi AH, Grulkowski I, Lu CD, Mohler KJ, et al. Choroidal analysis in healthy eyes using swept-source optical coherence tomography compared to spectral domain optical coherence tomography. Am J Ophthalmol. 2014;157:1272-81.e1. https://doi.org/10.1016/j.ajo.2014.02.034

31. Zhang L, Buitendijk GH, Lee K, Sonka M, Springelkamp H, Hofman A, et al. Validity of automated choroidal segmentation in SS-OCT and SD-OCT. Invest Ophthalmol Vis Sci. 2015;56:3202-11. https://doi.org/10.1167/iovs.14-15669

32. Philip AM, Gerendas BS, Zhang L, Faatz H, Podkowinski D, Bogunovic $\mathrm{H}$, et al. Choroidal thickness maps from spectral domain and swept source optical coherence tomography: algorithmic versus ground truth annotation. Br J Ophthalmol. 2016;100:1372-6. https:// doi.org/10.1136/bjophthalmol-2015-307985

33. Karapetyan A, Ouyang P, Tang LS, Gemilyan M. Choroidal thickness in relation to ethnicity measured using enhanced depth imaging optical coherence tomography. Retina. 2016;36:82-90. https://doi.org/10.1097/iae.0000000000000654

34. Phasukkijwatana N, Thaweerattanasilp W, Laotaweerungsawat S, Rodanant N, Singalavanija A, Tanterdtham J, et al. Enhanced depth imaging spectral-domain optical coherence tomography of the choroid in Thai population. J Med Assoc Thai. 2014;97:947-53.

35. Jirarattanasopa P, Panon N, Hiranyachattada S, Bhurayanontachai P. The normal choroidal thickness in southern Thailand. Clin Ophthalmol. 2014;8:2209-13. https://doi.org/10.2147/opth.s71343

36. Zafar S, Siddiqui MR, Shahzad R. Comparison of choroidal thickness measurements between spectral-domain OCT and swept-source OCT in normal and diseased eyes. Clin Ophthalmol. 2016;10:2271-6. https://doi.org/10.2147/opth.s117022 
37. Copete S, Flores-Moreno I, Montero JA, Duker JS, Ruiz-Moreno JM. Direct comparison of spectral-domain and swept-source OCT in the measurement of choroidal thickness in normal eyes. Br J Ophthalmol. 2014;98:334-8. https://doi.org/10.1136/ bjophthalmol-2013-303904

38. Matsuo Y, Sakamoto T, Yamashita T, Tomita M, Shirasawa M \& Terasaki H. Comparisons of choroidal thickness of normal eyes obtained by two different spectral-domain OCT instruments and one swept-source OCT instrument. Invest Ophthalmol Vis Sci. 2013;54:7630-6. https://doi.org/10.1167/iovs.13-13135

39. Gupta $\mathrm{P}$, Jing $\mathrm{T}$, Marziliano $\mathrm{P}$, Cheung CY, Baskaran $\mathrm{M}$, Lamoureux EL, et al. Distribution and determinants of choroidal thickness and volume using automated segmentation software in a population-based study. Am J Ophthalmol. 2015;159:293-301.e3. https://doi.org/10.1016/j.ajo.2014.10.034

40. Barteselli G, Chhablani J, El-Emam S, Wang H, Chuang J, Kozak I, et al. Choroidal volume variations with age, axial length, and sex in healthy subjects: a three-dimensional analysis. Ophthalmology. 2012;119:2572-8. https://doi.org/10.1016/j.ophtha.2012.06.065

41. Tuncer I, Karahan E, Zengin MO, Atalay E, Polat N. Choroidal thickness in relation to sex, age, refractive error, and axial length in healthy Turkish subjects. Int Ophthalmol. 2015;35:403-10. https://doi.org/10.1007/s10792-014-9962-4

42. Cooke JP, Creager MA, Osmundson PJ, Shepherd JT. Sex differences in control of cutaneous blood flow. Circulation. 1990;82:1607-15.

43. Ovet G, Alpfidan I, Sakarya Y, Sakarya R, Ozcimen M, Goktas S, et al. The acute effect of pseudoephedrine on choroidal thickness. Clin Ter. 2016;167:63-66. https://doi.org/10.7417/ct. 2016.1927

44. Michalewski J, Michalewska Z, Nawrocka Z, Bednarski M, Nawrocki J. Correlation of choroidal thickness and volume measurements with axial length and age using swept source optical coherence tomography and optical low-coherence reflectometry. Biomed Res Int. 2014;2014:639160

45. Ramrattan RS, van der Schaft TL, Mooy CM, de Bruijn WC, Mulder PG \& de Jong PT. Morphometric analysis of Bruch's membrane, the choriocapillaris, and the choroid in aging. Invest Ophthalmol Vis Sci. 1994;35:2857-64.

46. Wakatsuki Y, Shinojima A, Kawamura A, Yuzawa M. Correlation of aging and segmental choroidal thickness measurement using swept source optical coherence tomography in healthy eyes. PLoS ONE. 2015;10:e144156. https://doi.org/10.1371/journal.pone.0144156

47. Moussa M, Sabry D, Soliman W. Macular choroidal thickness in normal Egyptians measured by swept source optical coherence tomography. BMC Ophthalmol. 2016;16:138

48. Ding X, et al. Choroidal thickness in healthy Chinese subjects. Invest Ophthalmol Vis Sci. 2011;52:9555-60. https://doi.org/10. 1167/iovs.11-8076

49. Gallego-Pinazo R, Dolz-Marco R, Gómez-Ulla F, Mrejen S, Freund KB. Pachychoroid diseases of the macula. Med Hypothesis Discov Innov Ophthalmol. 2014;3:111.

50. Phasukkijwatana N, Freund KB, Dolz-Marco R, Al-Sheikh M, Keane PA, Egan CA, et al. Peripapillary pachychoroid syndrome. Retina. 2018;38:1652-67.

51. Koo TK, Li MY. A guideline of selecting and reporting intraclass correlation coefficients for reliability research. J Chiropr Med. 2016;15:155-63. https://doi.org/10.1016/j.jcm.2016.02.012

52. Wang J, Gao X, Huang W, Wang W, Chen S, Du S, et al. Sweptsource optical coherence tomography imaging of macular retinal and choroidal structures in healthy eyes. BMC Ophthalmol. 2015;15:122. https://doi.org/10.1186/s12886-015-0110-3

53. Akhtar Z, Rishi P, Srikanth R, Rishi E, Bhende M \& Raman R. Choroidal thickness in normal Indian subjects using Swept source optical coherence tomography. PLoS ONE. 2018;13:e0197457. https://doi.org/10.1371/journal.pone.0197457 